2016-4

\title{
A Cross-cultural Examination of Preferences for Work Attributes
}

\author{
Melissa S. Woodard \\ University of Massachusetts - Amherst \\ Jane K. Miller \\ University of Massachusetts - Amherst \\ Daniel Miller \\ Central Connecticut State University
}

See next page for additional authors

Follow this and additional works at: https://arrow.tudublin.ie/buschmarart

Part of the Business Administration, Management, and Operations Commons, International Business Commons, and the Organizational Behavior and Theory Commons

\section{Recommended Citation}

Woodard, M.S., Miller, J.K., Miller, D.J., Silvernail, K.D., Guo, C., Nair, S., Aydin, M.D., Lemos, A.H., Donnelly, P.F., Kumpikatie-Valiuniene, V., Marx, R. and Peters, L.M. (2016) A Cross-Cultural Examination of Preferences for Work Attributes. Journal of Managerial Psychology, 31(3): 702-719, 2016. DOI is 10.1108/JMP-09-2013-0289

This Article is brought to you for free and open access by the School of Marketing at ARROW@TU Dublin. It has been accepted for inclusion in Articles by an authorized administrator of ARROW@TU Dublin. For more information, please contact arrow.admin@tudublin.ie, aisling.coyne@tudublin.ie,gerard.connolly@tudublin.ie.

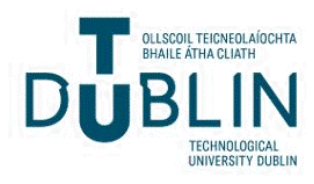




\section{Authors}

Melissa S. Woodard, Jane K. Miller, Daniel Miller, Kirk D. Silvernail, Chun Guo, Sudhir Nair, Mehmet Devrim Aydin, Ana Helosia da Costa Lemos, Paul Donnelly, Vilmante Kumpikaite, Robert Marx, and Linda M.

Peters

This article is available at ARROW@TU Dublin: https://arrow.tudublin.ie/buschmarart/133 
Published in Journal of Managerial Psychology, Vol. 31 No. 3, 2016, pp. $702-719$

DOI 10.1108/JMP-09-2013-0289

A Cross-Cultural Examination of Preferences for Work Attributes

\author{
Melissa S. Woodard \\ Department of Management \\ University of Massachusetts \\ Isenberg School of Management \\ Amherst, MA 01003 \\ USA \\ Jane K. Miller \\ Department of Management \\ University of Massachusetts \\ Isenberg School of Management \\ Amherst, MA 01003 \\ USA \\ Daniel J. Miller \\ Department of Management and Organization \\ School of Business \\ Central Connecticut State University \\ New Britain, CT 06050 \\ USA \\ Kirk D. Silvernail \\ Department of Management \\ University of Massachusetts \\ Isenberg School of Management \\ Amherst, MA 01003 \\ USA \\ Chun Guo \\ Department of Management \\ John F. Welch College of Business \\ Sacred Heart University \\ Fairfield, CT 06825 \\ USA \\ Sudhir Nair \\ Peter B. Gustavson School of Business \\ University of Victoria \\ Victoria, BC, V8W2Y2 \\ Canada
}


Mehmet Devrim Aydin

Department of Political Science and Public Administration

Faculty of Economics and Administrative Sciences

Hacettepe University

Ankara

Turkey

Ana Heloisa da Costa Lemos

IAG School of Management

Pontifícia Universidade Católica do Rio de Janeiro

Rio de Janeiro

Brazil 22451-900

Paul F. Donnelly

College of Business

Dublin Institute of Technology

Dublin 2

Ireland

Vilmante Kumpikaite-Valiuniene

Department of Management

Economics and Business School

Kaunas University of Technology

Kaunas

Lithuania 44309

Robert Marx

Department of Management

University of Massachusetts

Isenberg School of Management

Amherst, MA 01003

USA

Linda M. Peters

Department of Management

University of Massachusetts

Isenberg School of Management

Amherst, MA 01003

USA

Corresponding author: Melissa S. Woodard

Corresponding Author's Email: mwoodard@isenberg.umass.edu 


\title{
A Cross-Cultural Examination of Preferences for Work Attributes
}

\begin{abstract}
Purpose: We examine the relationship between individual- and country-level values and preferences for job/organizational attributes.

Design/methodology: Survey data were collected from 475 full-time employees (average of 9 years work experience, and 3 years in a managerial position) enrolled in part-time MBA programs in seven countries.

Findings: Preference for a harmonious workplace is positively related to horizontal collectivism, whereas preference for remuneration/advancement is positively related to vertical individualism. We also find a positive relationship between preference for meaningful work and horizontal individualism, and between preference for employer prestige and social adjustment needs. Research limitations/implications: Although our sample comprised experienced, full-time professionals, using graduate business students may limit generalizability. Overall, our results provide initial support for the utility of incorporating the multidimensional I/C measure, as well as social adjustment needs, when assessing the relationships between values and employee preferences.
\end{abstract}

Practical implications: For practitioners, the primary conclusion is that making assumptions about preferences based on nationality is risky. Findings may also prove useful for enhancing person-organization fit and the ability to attract and retain qualified workers.

Originality/value: This study extends research on workers' preferences by incorporating a new set of values and sampling experienced workers in a range of cultural contexts.

Keywords: Worker preferences, individualism/collectivism, social adjustment Article Classification: Research paper 


\section{Introduction}

Researchers have long been interested in the factors that influence individuals' attraction to organizations (Breaugh, 2008; Uggerslev, Fassina and Kraichy, 2012). Of particular interest to the present study is research on the relation of personal values to individuals' preferences for various organizational and job attributes (Cable and Judge, 1994; 1996; Ehrhart and Ziegert, 2005; Hult, 2005). Much of the past research that examined these relationships focused on undergraduate students, with limited workplace experience (Breaugh, 2008). Moreover, crosscultural research on the relationship between values and work preferences, particularly for graduate students, who represent an important segment of job-seekers, is "scant" (Caligiuri, Colakoglu, Cerdin and Kim, 2010:138).

This study extends research on workers' attribute preferences by examining the impact of personal values among experienced workers, in both Western and non-Western contexts. Values, defined here as desirable end states that guide individual attitudes and behaviors, theoretically affect the valence of various job and organizational attributes (Feather, 1995; Rokeach, 1973; Stone, Stone-Romero and Lukaszewski, 2007). Our premise is that values constitute the cognitive lens through which individuals evaluate work environments. That is, individuals' values affect how they cognitively process and evaluate work-related information (what is salient, how it is interpreted) (Feather, 1995; Thomas, Au and Ravlin, 2003). People are assumed to make choices that enable them to maintain a positive self-image, but their beliefs about which of their options will achieve this goal vary according to their values (Thomas et al., 2003). For example, individuals with collectivist values interpret information about a training program in terms of whether participation will contribute to group (versus personal) goals, and therefore whether or not it is desirable (Thomas et al., 2003). 
Using survey data collected from working professionals enrolled in part-time MBA programs in 7 countries, we assess the relationship between a set of individual- and country-level values and preferences for organizational and job attributes. The countries - China, Brazil, Ireland, Turkey, India, United States, and Lithuania - were selected based on the goal of obtaining considerable diversity in cultural values. We used working professionals in order to tap the values and preferences of individuals with work experience.

\section{Theory and hypotheses development}

As discussed above, the theoretical premise underlying our study is that individuals are programmed to evaluate organizational and job attributes in accordance with their values. Here, we examine the relationship between values and preferences for four attributes: harmonious work environment, meaningful work, remuneration/advancement opportunities, and employer prestige. Adopted from the Caligiuri et al. (2010) study, these four attributes have also consistently appeared as important in related studies (Uggerslev et al., 2012). We next discuss the specific values we believe play an important role in explaining preferences for these attributes.

\section{Horizontal and vertical $\mathrm{I} / \mathrm{C}$}

Individualism and collectivism (I/C) are perhaps the most widely studied values in crosscultural research (Gouveia, Clemente and Espinosa, 2003; Kirkman, Lowe and Gibson, 2006) and significant variations in $\mathrm{I} / \mathrm{C}$ have been observed both within and between countries (Hofstede, 1980; Schwartz, 1999). This pattern of variation is attributed to the simultaneous influences of a nation's institutions (e.g., schools, churches), presumably reflecting the shared values of the culture within which they are embedded, and an individual's "idiosyncratic experiences and personality" (Schwartz, 1999; Thomas et al., 2003: 455). Accordingly, we 
expect that preferences for job and organizational attributes will be influenced by shared, cultural-level values and individual-level values.

Concerns about the lack of fidelity in one- and two-dimensional measures of I/C led to the creation of a more nuanced measure that distinguishes between vertical and horizontal I/C (Singelis, Triandis, Bhawuk and Gelfand, 1995). The measure captures individual variation in both the importance of the group and views about social equality (Singelis et al., 1995; Triandis, 1996). The vertical/horizontal dimension captures individuals' views about equality, with Horizontals emphasizing equality and Verticals emphasizing inequality (hierarchy) within a group. Incorporating this dimension into the $\mathrm{I} / \mathrm{C}$ construct results in four quadrants: vertical individualism (VI), horizontal individualism (HI), vertical collectivism (VC), and horizontal collectivism (HC). Horizontal individualism emphasizes individual autonomy and equality in status with others. Vertical collectivists emphasize loyalty to the in-group, but expect inequality in status within the group. Several studies found empirical support for the multidimensional I/C construct (Gardner, Reithel, Foley, Cogliser and Walumbwa, 2009; Gouveia et al., 2003; Triandis and Gelfand, 1998).

Limited research has examined the relationships between cultural- and individual-level I/C and preferences for various job attributes (Cable and Judge, 1994; Parkes, Bochner, and Schneider, 2001). Research using the multidimensional I/C construct is sparse. One study (Caligiuri, et al., 2010) surveyed graduate students to examine the relationship between culturallevel emphasis on individualism and verticalness and the importance of employer reputation when choosing the "ideal employer." Acknowledging the study relied on indirect measures of multidimensional $\mathrm{I} / \mathrm{C}$, the authors recommended incorporating "a more accurate assessment of individuals' cultural values" (Caligiuri et al., 2010: 146). Another study (Gardner et al., 2009) 
relied on individual-level data from undergraduate students to examine the relationship between the attractiveness of different organizational culture types and the four I/C quadrants. Since prior research established that $\mathrm{I} / \mathrm{C}$ variations are predictive of job attribute preferences and recent developments suggest the multidimensional I/C construct could deepen our understanding of this relationship, we include horizontal and vertical I/C as explanatory variables in our model. We next consider the relationships at the national and individual levels between these values and preferences for organizational and job attributes.

Preferences for harmonious work environment. Whether and how individuals evaluate a work environment in terms of its friendliness, or harmony, is theoretically influenced by the value they attach to the group (Thomas et al., 2003). Collectivists believe in "the fundamental connectedness of human beings to each other ... [and] a normative imperative ... to maintain this interdependence among individuals" (Gouveia et al., 2003; Markus and Kitayama, 1991: 227). As such, both horizontal and vertical collectivists tend to focus on information relevant to their desire to maintain lasting relationships and, hence, on the relational elements of work environments (Thomas et al., 2003). Accordingly, horizontal and vertical collectivists tend to score high on survey items tapping sociability (Triandis and Gelfand, 1998). Horizontal and vertical collectivists are expected to be particularly concerned about workgroup harmony.

H1a: Individual-level horizontal and vertical collectivism are positively related to preferences for a harmonious work environment.

At the country level, institutional influences guide individuals to focus on information consistent with prevailing values. In collectivist countries, individuals are repeatedly exposed to the principle that maintenance of the collective is of utmost importance. 
HIb: Respondents from countries high on collectivism (Brazil, Turkey, India and China) are more likely to exhibit strong preferences for a harmonious work environment than are respondents from the other countries.

Horizontal and vertical collectivists differ in their views about the relative status of individuals in a group. Horizontal collectivists emphasize equality within groups. Such individuals "see themselves as being similar to others ... and emphasize common goals with others, interdependence, and sociability" (Triandis and Gelfand, 1998: 119). In contrast, vertical collectivists accept inequality, and emphasize competition (Singelis et al., 1995). Additonally, vertical collectivists emphasize loyalty to the in-group but also competition with out-groups (Triandis and Gelfand, 1998). For vertical collectivists, then, harmony may be less of a concern than it is for horizontal collectivists.

H2: The magnitude of the relationship between (individual-level) horizontal collectivism and preferences for a harmonious work environment is greater than the relationship between (individual-level) vertical collectivism and preferences for a harmonious work environment.

Preferences for remuneration and advancement. More than any other group, vertical individualists are oriented towards individual achievement (Gouveia et al., 2003; Triandis and Gelfand, 1998). As individualists, their focus is short-term, individual gain; accordingly, they are most interested in the transactional (monetizable) elements of work arrangements (Thomas et al., 2003). Vertical individualists are characterized as competitive and hedonistic (Triandis and Gelfand, 1998), accepting low equality and preferring pay based on individual contribution (Khatri, Tsang and Begley, 2006). Hence, to the extent that good pay and advancement 
opportunities allow individuals to distinguish themselves and acquire material goods, such offerings should be particularly important to vertical individualists. ${ }^{1}$

H3: Individual-level vertical individualism is positively related to preferences for remuneration and opportunities for advancement.

Preferences for meaningful work. We believe that preferences for meaningful work are linked to individualism, but find no theoretical basis for differences along the verticalness dimension. Individualists give priority to personal goals (Thomas et al., 2003; Triandis, 1996). As such, they are interested in their own "self-actualization" and uniqueness (Markus and Kitayama, 1991: 226). In contrast, collectivists evaluate elements of the work environment in terms of their potential benefit to the group, and expect individual sacrifices in order to maximize group outcomes (Thomas et al., 2003). Positively contributing to the group is more important than finding meaning in one's work.

H4a: Horizontal and vertical individualism (individual-level) are positively related to preferences for meaningful work.

H4b: Respondents from countries high on individualism (U.S., Ireland, and Lithuania) are more likely to exhibit strong preferences for meaningful work than are respondents from other countries.

Preferences for employer prestige. We expect employer prestige to be most important to vertical collectivists. For collectivists, the group's accomplishment is more imperative than the individual's and, because membership is "idealized as eternal," group outcomes are especially consequential (Thomas et al., 2003: 455). Vertical collectivists accept inequality (Singelis et al., 1995) and "seek to maximize in-group success" in competition with out-groups," resulting in

\footnotetext{
${ }^{1}$ We do not posit a parallel, country-level relationship for VI since research suggests that HI and $\mathrm{VC}$ are the predominant patterns observed at the national level (Thomas and Au, 2002).
} 
“intergroup competition for status" (Khatri et al., 2006: 68-69). In contrast, personal success and short-term transactional rewards are more important to individualists (Thomas et al., 2003). Taken together,

H5a: Vertical collectivism (individual-level) is positively related to preferences for employer prestige.

H5b: Respondents from countries high on vertical collectivism (China, India) are more likely to exhibit strong preferences for employer prestige than are respondents from other countries.

\section{Social adjustment needs}

Expanding on recent conceptualizations that distinguish between instrumental (e.g. pay) and symbolic (e.g. prestige and reputation) organizational attributes (Lievens and Highhouse, 2003), Highhouse, Thornbury and Little (2007) developed a model that explicates the motives underlying individuals' symbolic attraction to organizations. The authors argue that individuals make "symbolic inferences" about an organization based on "market signals" such as compensation policies (Highhouse et al., 2007: 137). They might infer that an organization known to be a "compensation leader" is an "impressive company" (Highhouse et al., 2007: 137). Whether such an organization is attractive to an individual would depend, in part, on the underlying motive. One of the posited motives is a "concern for social adjustment," whereby individuals are concerned with maintaining a positive self-image by impressing others (Highhouse et al., 2007: 137), sometimes by affiliating with prestigious organizations.

Limited research has found support for a relationship between social adjustment needs and the attractiveness of a prestigious company (Highhouse et al., 2007), although we know of no related cross-cultural study. We believe that social adjustment needs is a lens through which 
certain individuals evaluate organizational and job attributes. According to Highhouse et al. (2007: 138), individuals with high social adjustment needs tend to be preoccupied "with external indicators of status and prestige" such as "money or material goods." Hence, they will prefer those job/organizational attributes that they believe will convey the most status.

H6: Social adjustment values are positively related to preferences for employer prestige.

H7: Social adjustment values are positively related to preferences for remuneration and opportunities for advancement.

\section{Method}

Sample and Procedure

Data were collected from working professionals in seven countries (Brazil, China, India, Ireland, Lithuania, Turkey and the U.S.) selected to enhance cultural diversity. Hofstede's country-level measures of I/C range from 20 (China) to 91 (U.S.), and power distance (verticalness) ranges from 28 (Ireland) to 80 (China). ${ }^{2}$ The countries are geographically dispersed on four continents. Participants had an average work experience of 9 years (4.3 years in managerial positions) and were enrolled in part-time MBA programs.

The English version of the survey was used in the U.S., India, and Lithuania. In the remaining countries, the survey was translated into the local language using back-translation techniques (Brislin, 1970). To reduce common-method variance, surveys were administered in two stages. The first survey collected demographic and cultural values information. The second survey collected work attribute preferences two weeks later. Non-native respondents were deleted from the analysis. The number of matched, completed surveys were: Brazil (51), China

\footnotetext{
${ }^{2}$ Scores were obtained from The Hofstede Centre, available at http://geerthofstede.com/countries.html
} 
(66), India (52), Ireland (45), Lithuania (77), Turkey (83), and the U.S. (101). The sample was $45 \%$ female, with an average age of 30 years.

\section{Measures: Independent variables}

Our multi-dimensional IC measure was taken from Triandis (1996) and the social adjustment scale from Highhouse et al. (2007). All scales used a 6-point Likert scale (1 = strongly disagree, $6=$ strongly agree).

Cultural equivalence tests. Since our study involves cross-cultural comparisons among seven country groups, we first examined the cultural invariance of measures for independent variables (social adjustment and the four I/C quadrants) using structural equation modeling (AMOS, 22.0). Following the steps of Byrne (2008) and Byrne (2009), we first established configural equivalence (determining whether the factor loading pattern is the same across cultural groups). The configural model is a multi-group representation of the factor loading pattern and the fit of the configural model serves as the baseline for subsequent tests of equivalence. Once configural equivalence is established, measurement equivalence, the extent to which parameters comprising the measurement are similar across cultural groups, is examined. In a measurement model, parameters are estimated for the first group only and estimates for all remaining groups are constrained to equal those of the first group. If the chi-square difference value is statistically nonsignificant, full measurement equivalence is established. When the evidence of nonequivalence of all factor loadings of a measurement is identified (i.e., the $\chi^{2}$ difference value is statistically significant), subsequent tests are conducted until partial measurement equivalence can be established. We followed these steps for each of the independent variables in our study. 
Results indicate configural equivalence for all variables: social adjustment $(\chi 2=31.929$, $\mathrm{df}=14, \mathrm{GFI}=.971, \mathrm{CFI}=.976$, and RMSEA $=.051), \mathrm{HI}(\chi 2=32.51, \mathrm{df}=14, \mathrm{GFI}=.970, \mathrm{CFI}=$ $.959, \mathrm{RMSEA}=.051), \mathrm{HC}(\chi 2=29.239, \mathrm{df}=14, \mathrm{GFI}=.974, \mathrm{CFI}=.955, \mathrm{RMSEA}=.046), \mathrm{VC}$ $(\chi 2=7.943, \mathrm{df}=14, \mathrm{GFI}=.993, \mathrm{CFI}=1.0, \mathrm{RMSEA}=.000)$, and VI $(\chi 2=46.894, \mathrm{df}=35, \mathrm{GFI}$ $=.965, \mathrm{CFI}=.968, \mathrm{RMSEA}=.026)$.

Having established goodness-of-fit for the configural model of each variable, we assessed measurement model equivalence to examine whether parameters in the measurement model are equivalent across cultural groups. To assess the measurement model equivalence of each variable, we tested a series of models where equality constraints were imposed on particular parameters, and conducted chi-square difference tests between these models and the configural model to identify specific items that are culturally invariant. Specifically, we first imposed equality constraints on all factor loadings of a variable measurement across all cultural groups in our study. If the chi-square difference between this model and the configural model showed evidence of invariance (i.e., the $\chi^{2}$ difference value is nonsignificant) of all factor loadings, we concluded there was measurement equivalence. If the chi-square difference showed evidence of noninvariance of all factor loadings (i.e., the $\chi^{2}$ difference value is significant), we proceeded to test for the invariance of the factor loading of each item separately. If the evidence of measurement invariance was identified, we retained this item in the subsequent tests and imposed equality on an additional item.

Results indicate partial measurement equivalence for the social adjustment measure ${ }^{3}\left(\Delta \chi^{2}\right.$ $=9.268, \Delta \mathrm{df}=6$, n.s., GFI $=.964, \mathrm{CFI}=.971$, and RMSEA $=.046)$, the VI measure ${ }^{4}\left(\Delta \chi^{2}\right.$

\footnotetext{
${ }^{3}$ For the SA measure, the items "I wonder if strangers would be impressed by where I work" and "Working for an impressive organization would make me seem impressive to others" are culturally invariant.
} 
$=25.09, \Delta \mathrm{df}=18$, n.s., $\mathrm{GFI}=.948, \mathrm{CFI}=.949$, and RMSEA $=.027)$, the HI measure ${ }^{5}(\Delta \chi 2$ $=6.401, \Delta \mathrm{df}=6$, n.s., GFI $=.963, \mathrm{CFI}=.958$, and RMSEA $=.043$ ); and full measurement equivalence for the $\mathrm{HC}$ measure $(\Delta \chi 2=22.358, \Delta \mathrm{df}=18$, n.s., $\mathrm{GFI}=.954, \mathrm{CFI}=.942$, and $\mathrm{RMSEA}=.034)$ and the $\mathrm{VC}$ measure $(\Delta \chi 2=18.994, \Delta \mathrm{df}=18$, n.s., $\mathrm{GFI}=.975, \mathrm{CFI}=1.000$, and RMSEA $=.000)$. Since at least two items for each measure were culturally invariant, we followed the guidelines of Steenkamp and Baumgartner (1998) and concluded that all study measures were sufficiently equivalent for testing. Scalar equivalence was established using the steps recommended by Hult et al. (2008).

Intraclass correlations. Following Caligiuri et al. (2010), we estimated intraclass correlations (ICC [1]) to test for non-independence of our independent variables due to the nesting of individuals in countries. Tests of non-independence were not significant for VC, VI, $\mathrm{HC}$ and SA (ICC $[1]=-0.09, .00, .00$ and .00 , respectively) but was significant for $\mathrm{HI}(0.25, \mathrm{p}<$ .01 ) although the eta-square was only .06 . Based on these results we concluded that nonindependence was not a threat to our findings. At the same time, the lack of agreement among individuals within these countries indicates that national-level analysis is not appropriate. ${ }^{6}$ Accordingly, we did not test our country-level hypotheses (H1b, H4b, and H5b).

Scales. Vertical collectivism was measured using 4 items $(\alpha=.54)$. A sample item is "It is important to me that I respect the decisions made by my group." Vertical individualism was measured with 5 items $(\alpha=.69)$. A sample item is "It is important that I do my job better than

\footnotetext{
${ }^{4}$ For the VI measure, the items "I enjoy working in situations involving competition with others," "Competition is the law of nature," "Winning is everything", and "It is important that I do my job better than others" are culturally invariant.

${ }^{5}$ For the HI measure, "I enjoy being unique and different from others" and "Being a unique individual is important to me" are culturally invariant.

${ }^{6}$ ICC values were higher when respondents were grouped according to country-level values (e.g., all respondents living in countries high on collectivism), however analyses of country-level effects yielded non-significant results.
} 
others." Horizontal individualism was measured with 4 items $(\alpha=.73)$. A sample item is "Being a unique individual is important to me." Horizontal collectivism was measured with 4 items ( $\alpha=$ .65). A sample item is "It is important to me to maintain harmony within my group."

Social adjustment (SA) values were measured using 4 items $(\alpha=.65)$. A sample item is "Working for an impressive company would make me seem impressive to others."

Measures: Dependent variables

We assessed preferences for four work attributes, based on the work by Caligiuri et al. (2010): harmonious work environment, remuneration and advancement opportunities, meaningful work, and employer reputation. Respondents were instructed to allocate 100 points across the 4 attributes according to their preferences, with the most points given to the most important attribute.

Measures: Control variables

Control variables included age, gender, and years of work experience.

\section{Results}

The correlation matrix is presented in Table 1. Country means are reported in Table 2.

Insert Tables 1 and 2 here

Consistent with previous studies examining the relationship between I/C and career/job preferences, we used hierarchical regression analysis to test our hypotheses (see, e.g., Caligiuri et al., 2010; Gomez, 2003). Point allocations (preferences) for each attribute were regressed on control variables in Model 1. The four individual-level I/C values were added in Model 2, and social adjustment was added in Model 3. The results are presented in Tables 3a, 3b, 3c, and 3d.

Insert Tables 3a, 3b, 3c, and 3d here 
In Table 3a, preferences for a harmonious work environment are positively and significantly related to $\mathrm{HC}$, but not VC, partially supporting H1a. A Chow's-test of HC/VC beta coefficients indicated they were not significantly different from each other, thereby failing to support H2. Results for remuneration/opportunities for advancement support our hypothesis (H3) of a positive relationship with VI, but not our hypothesis (H7) of a positive relationship with social adjustment (Table 3b). The relationship between preferences for meaningful work and individualism is positive and significant for HI, but insignificant for VI, providing partial support for H4a. Results for employer prestige (Table 3d) indicate a positive, significant relationship with social adjustment values (H6), as we predicted. The relationship between preferences for employer prestige and VC (H5a) is significant in Model 2, but dropped out after we added social adjustment values, suggesting that SA is the primary predictor for this attribute. Hence, H5a was partially supported.

None of the control variables were significant in the analyses.

\section{Discussion}

The purpose of our study was to assess the extent to which preferences for various job and organizational attributes could be explained by cultural values and social identity needs. We found support for our hypothesized relationships between I/C values and preferences for 3 of the 4 attributes (work environment, remuneration/advancement opportunities, and meaningful work), and between social adjustment values and employer prestige.

We predicted that preferences for remuneration/advancement opportunities are tied to both social adjustment and VI, and that preferences for employer prestige would be tied to both social adjustment and VC. We found, though, that preference for remuneration was not linked to 
SA, and that preference for prestige was not linked to VC. Our findings suggest that employer prestige is perhaps a more visible indicator of success than is pay and position. Since individuals with high social adjustment needs are most concerned with impressing others, a preference for employer prestige above all else may make sense. Further, the collectivist concern with maintaining long-term relationships is a higher priority (hence the significant relationship with harmonious work environment) for VCs than is working for a prestigious employer.

We found a number of significant relationships that were not predicted, but are not surprising. The negative and significant relationship between VI and preference for a harmonious work environment, for instance, suggests that the strong emphasis VIs place on individual achievement dwarfs any interest in other attributes that do not provide visible evidence of success. Similarly, the negative relationships between horizontal individualism and collectivism and preference for remuneration/advancement opportunities is consistent with the emphasis by this group on equality rather than individual achievement. Finally, the negative relationship between social adjustment needs and preference for meaningful work is not surprising, given the primary importance that individuals with high social adjustment needs attach to prestige.

\section{Limitations}

As with all studies, ours is not without limitations. First, our relatively low effect sizes and $\mathrm{R}^{2}$ values suggest that our model does not fully capture the factors that explain workers' preferences. However, omitted variables are only a problem if there is any reason to believe that they are correlated with model variables. We have no reason to believe that other factors which have been shown to be related to preferences are correlated with the variables we included. Further, our results are similar in size to those found in previous research on the $\mathrm{I} / \mathrm{C}$ variable in 
general (Taras, Kirkman and Steel, 2010) and more specifically on its relationship with career/job preferences (e.g., Caligiuri et al., 2010; Gomez, 2003). In a meta-analysis of studies examining the I/C variable, Taras et al. (2010: 428) concluded that although "the absolute average effect size for cultural values at the individual level of analysis . . . can be characterized as relatively low," the amounts of variance they can explain "are as much as (and sometimes more than) that explained by" a variety of other factors. Accordingly, they argue that "cultural values are just as meaningful explanatory factors as are other individual differences" (Taras et al., 2010: 429).

Second, our sample comprised working professionals enrolled in graduate business classes; therefore generalizability is unclear. It is possible, for example, that the almost uniformly high preference for remuneration/advancement opportunities among our respondents is specific to business students as compared to students in other disciplines. Further, exposure to marketdriven economic principles in business schools may be creating some convergence of views about work among this population, as evidenced by very little cross-country variation. Nonetheless, this is an important cohort of job-seekers and the values they hold, regardless of source, are important to the organizations who recruit them (Caligiuri et al., 2010).

Third, within-country sample sizes in our study are relatively small, ranging from a low of 45 (Ireland) to a high of 101 (U.S.), perhaps making cross-country differences difficult to detect. Finally, the reliability of VC is fairly low (.54) in our study, suggesting caution in interpreting those results. We suspect that larger within-country sample sizes would have yielded more robust measures.

Small sample sizes may have also biased our cultural equivalence tests. Research evidence clearly suggests that sample size affects the power and precision of measurement 
invariance tests (Meade and Bauer, 2007). What is less clear is what minimum size is sufficient for an acceptable analysis. In a study addressing the issue of sample size adequacy in tests of measurement invariance, Meade and Bauer (2007) found that larger samples were consistently associated with smaller standard error values than smaller samples, but reached no conclusions about the appropriate minimum size.

\section{Implications for Research and Practice}

Our results provide some initial support for the utility of the multidimensional I/C measure when assessing the relationships between values and employee outcomes. We found a few differences in the preferences of vertical vs. horizontal individualists. Specifically, VI is positively related, whereas $\mathrm{HI}$ is negatively related, to preferences for remuneration/opportunities for advancement. Similarly, VI is unrelated, and HI is positively related, to preferences for meaningful work. Overall, these findings are consistent with other studies that supported the use of multidimensional I/C in cross-cultural research (Gouveia et al., 2003; Gardner et al., 2009; Soh and Leong, 2002). What remains unclear, however, is the extent to which adding the verticalness dimension to measures of $\mathrm{I} / \mathrm{C}$ is fully capturing the variance within the individualism and collectivism constructs. That is, although there is growing consensus that the $\mathrm{I} / \mathrm{C}$ construct is multidimensional, and that the four quadrant measure proposed by Singelis et al. (1995) provides a better fit in measuring these values than the one- or two-dimensional models, some researchers have suggested that the measure needs further refinement (Li and Aksoy, 2007; Soh and Leong, 2002). In particular, questions have been raised about the precision with which the verticalness dimension is being measured ( $\mathrm{Li}$ and Aksoy, 2007; Soh and Leong, 2002). Such lack of precision could help explain the relatively low reliability coefficients we obtained for these values. Research that explores the efficacy of alternative measures is clearly indicated. 
Our findings are consistent with, and extend, the limited research on the relationship between the four I/C values and workers' preferences. Gardner et al. (2009, p. 462) found a significant, positive relationship between $\mathrm{HC}$ and attraction to organizations with a "family-like atmosphere." The relationship was negative for VI (relationships with VC and $\mathrm{HI}$ were not tested). These results are remarkably similar to the relationships we found between these two values ( $\mathrm{HC}$ and $\mathrm{VI})$ and preferences for a harmonious work environment. Unlike the Gardner et al. (2009) study, which sampled undergraduate students in a single country (U.S.), our study sampled working professionals from multiple countries. Hence, the present study extends knowledge about these relationships to a broader population. We also provide new information about the relative importance of $\mathrm{I} / \mathrm{C}$ values in explaining preferences for employer prestige. Caligiuri et al. (2010) predicted that verticalists and collectivists would place the most emphasis on employer reputation. They found a small, but significant, relationship (negative) between national-level individualism and the importance of employer reputation. The predicted (positive) relationship with (national-level) verticalness was only significant in the model that did not include individualism. In our study, and consistent with Caligiuri et al.'s (2010) prediction, we found a significant, positive relationship between individual-level VC and employer prestige but only in the absence of social adjustment needs. After entering SA into the model (Model 3, Table 3d), VC dropped out as a significant predictor, SA became the only significant predictor, and the amount of variance explained increased significantly. These results are consistent with the work of Highhouse et al. (2007), who found a strong, positive relationship between SA and employer "impressiveness" among undergraduate students from the U.S. Our study extends these findings to a multinational, more experienced sample. Together, these studies affirm the importance of SA needs in understanding workers' preferences. 
We believe our findings have important implications for practitioners. The primary conclusion should be that making assumptions about individual preferences based on nationality is inadvisable. For instance, the common assumption that collectivists put more emphasis on the success of the group rather than on individual achievement is not supported by our findings. We found no differences in the preferences for remuneration and advancement opportunity between respondents in individualist cultures (e.g., U.S.) and those in collectivist cultures (e.g., China). Further, our findings may be useful in enabling employers to maximize the fit between their employees and the work environment, thereby enhancing their ability to attract and retain qualified workers. That is, information about applicants' values can be used to identify individuals most likely to appreciate what a given employer is offering. Alternatively, employers interested in attracting a certain type of individual (e.g., a highly competitive vertical individualist) can use the growing body of knowledge regarding the link between personal values and preferences to establish practices most likely to attract them.

In conclusion, we believe that our findings make contributions to both theory and practice. We provide new information about the relationship between personal values and preferences for various job and organizational attributes across a broad range of cultures. Further, ours is one of only a few studies on preferences that incorporate the more nuanced, 4quadrant, measure of $\mathrm{I} / \mathrm{C}$, or that capture within-country variance by measuring these values at the individual level. Finally, our study is the first to consider the role of social adjustment needs in explaining worker preferences in a cross-cultural context. As such, our study expands our understanding of the role that personal values play in explaining workers' preferences in a range of cultural contexts. 


\section{References}

Breaugh, J. A. (2008), “Employee recruitment: current knowledge and important areas for future research”, Human Resource Management Review, Vol.18 No. 3, pp. 103-118.

Brislin, R.W. (1970), “Back-translation of cross-cultural research”, Journal of Cross-Cultural Research, Vol. 1 No. 3, pp. 185-216.

Byrne, B. M. (2008), “Testing for multigroup equivalence of a measuring instrument: a walk through the process", Psicothema, 2008, Vol.20 No. 4, pp. 872-882.

Byrne, B. M. (2009), Structural Equation Modeling with AMOS: Basic Concepts, Applications, and Programming, Routledge, New York.

Cable, D. and Judge, T. (1994), "Pay preferences and job search decisions: a person-organization fit perspective", Personnel Psychology, Vol. 47 No. 2, pp. 317-348.

Cable, D. and Judge, T. (1996), "Person-organization fit, job choice decisions and organizational entry”, Organizational Behavior and Human Decision Processes, Vol. 67 No. 3, pp. 294311.

Caligiuri, P., Colakoglu, S., Cerdin, J.L., and Kim, M. (2010), “Examining cross-cultural and individual differences in predicting employer reputation as a driver of employer attraction", International Journal of Cross Cultural Management, Vol. 10 No. 2, pp. 137-151.

Ehrhart, K.H. and Ziegert, J.C. (2005), “Why are individuals attracted to organizations?”, Journal of Management, Vol. 31 No. 6, pp. 901-919.

Feather, N.T. (1995), "Values, valences and choice: the influence of values on the perceived attractiveness and choice of alternatives", Journal of Personality and Social Psychology, Vol. 68 No. 6, pp. 1135-1151. 
Gardner, W.L., Reithel, B.J., Foley, R.T., Cogliser, C.C. and Walumbwa, F.O., (2009),

“Attraction to organizational culture profiles", Management Communication Quarterly, Vol. 22 No. 3, pp. 437-472.

Gomez, C. (2003), "The relationship between acculturation, individualism/collectivism, and job attribute preferences for Hispanic MBAs", Journal of Management Studies, Vol.40 No. 5, pp. 1089-1105.

Gouveia, V.V., Clemente, M. and Espinosa, P. (2003), “The horizontal and vertical attributes of individualism and collectivism in a Spanish population", The Journal of Social Psychology, Vol. 143 No. 1, pp. 43-63.

Highhouse, S., Thornbury, E.E. and Little, I.S. (2007), "Social-identity functions of attraction to organizations", Organizational Behavior and Human Decision Processes, Vol. 103 No. 1, pp. 134-146.

Hofstede, G. (1980), Culture's Consequences: International Differences in Work-related Values, Sage, Beverly Hills, CA.

Hult, C. (2005), “Organizational commitment and person-environment fit in six western countries”, Organization Studies, Vol. 26 No. 2, pp. 249-270.

Hult, G., Ketchen, D., Griffith, D., Finnegan, C., Gonzalez-Padron, T., Harmancioglu, N., Huang, Y., Talay, M. and Cavusgil, S. (2008), "Data equivalence in cross-cultural international business research: assessment and guidelines”, Journal of International Business Studies, Vol. 39 No. 6, pp. 1027-1044.

Khatri, N., Tsang, E., and Begley, T. (2006), “Cronyism: a cross-cultural analysis”, Journal of International Business Studies, Vol. 37 No. 1, pp. 61-75. 
Kirkman, B.L., Lowe, K.B. and Gibson, C.B. (2006), “A quarter century of Culture’s

Consequences: a review of empirical research incorporating Hofstede's cultural values framework”, Journal of International Business Studies, Vol. 37 No. 3, pp. 285-320.

Li, F. and Aksoy, L. (2007), "Dimensionality of individualism-collectivism and measurement equivalence of Triandis and Gelfand's scale", Journal of Business and Psychology, Vol. 21 No. 3, pp. 313-329.

Lievens, F. and Highhouse, S. (2003), "The relation of instrumental and symbolic attributes to a company’s attractiveness as an employer”, Personnel Psychology, Vol. 56 No. 1, pp. 75102.

Markus, H.R. and Kitayama, S. (1991), "Culture and the self: implications for cognition, emotion, and motivation”, Psychological Review, Vol. 98 No. 2, pp. 224-253.

Meade, A. W. and Bauer, D.J. (2007), "Power and precision in confirmatory factor analytic tests of measurement invariance", Structural Equation Modeling, Vol. 14 No. 3, pp. 611-635.

Parkes, L., Bochner, S. and Schneider, S. (2001), "Person-organisation fit across cultures: an empirical investigation of individualism and collectivism", Applied Psychology: An International Review, Vol. 50 No. 1, pp. 81-108.

Rokeach, M. (1973), The Nature of Human Values, Free Press, New York, NY.

Schwartz, S.H. (1999), “A theory of cultural values and some implications for work", Applied Psychology: An International Review, Vol. 48 No. 1, pp. 23-47.

Singelis, T., Triandis, H.C., Bhawuk, D., and Gelfand, M. (1995), "Horizontal and vertical individualism and collectivism: a theoretical and methodological refinement", CrossCultural Psychology, Vol. 29 No. 3, pp. 240-275. 
Soh, S. and Leong, F.T. (2002), "Validity of vertical and horizontal individualism and collectivism in Singapore: Relationships with values and interests", Journal of CrossCultural Psychology, Vol. 33 No. 1, pp. 3-15.

Steenkamp, J.E.M. and Baumgartner, H. (1998), “Assessing measurement invariance in crossnational consumer research" Journal of Consumer Research, Vol. 25 No. 1, pp. 78-107.

Stone, D., Stone-Romero, E. and Lukaszewski, M. (2007), "The impact of cultural values on the acceptance and effectiveness of human resource management policies and practices", Human Resource Management Review, Vol. 17 No. 2, pp. 152-165.

Taras, V., Kirkman, B.L. and Steel, P. (2010), “Examining the impact of Culture's Consequences: a three-decade, multilevel, meta-analytic review of Hofstede's cultural value dimensions", Journal of Applied Psychology, Vol. 95 No. 3, pp. 405-439.

Thomas, D.C. and Au, K. (2002), "The effect of cultural differences on behavioral responses to low job satisfaction", Journal of International Business Studies, Vol. 33 No. 2, pp. 309326.

Thomas, D.C., Au, K. and Ravlin, E.C. (2003), "Cultural variation and the psychological contract", Journal of Organizational Behavior, Vol. 24 No. 5, pp. 451-471.

Triandis, H. C. (1996), “The psychological measurement of cultural syndromes”, American Psychologist, Vol. 51 No. 4, pp. 407-415.

Triandis, H.C. and Gelfand, M. J. (1998), “Converging measurement of horizontal and vertical individualism and collectivism", Journal of Personality and Social Psychology, Vol. 74 No. 1, pp. 118-128. 
Uggerslev, K.L., Fassina, N.E. and Kraichy, D. (2012), "Recruiting through the stages: A metaanalytic test of predictors of applicant attraction at different stages of the recruiting process", Personnel Psychology, Vol. 65 No. 3, pp. 597-660.

\section{Web reference}

http://geert-hofstede.com/countries.html (accessed March 17, 2014). 
Table 1

Descriptive Statistics

\begin{tabular}{|c|c|c|c|c|c|c|c|c|c|c|c|c|c|c|c|c|c|c|c|c|}
\hline & Mean & s.d. & 1 & 2 & 3 & 4 & 5 & 6 & 7 & 8 & 9 & 10 & 11 & 12 & 13 & 14 & 15 & 16 & 17 & 18 \\
\hline 1 Harmonious Env. Points & 27.2 & 10.67 & & & & & & & & & & & & & & & & & & \\
\hline 2 Remuneration/Adv. Points & 31.48 & 11.61 & $-.46^{* *}$ & & & & & & & & & & & & & & & & & \\
\hline 3 Meaningful Work Points & 26.79 & 10.28 & $-.38^{* *}$ & $-.36^{* *}$ & & & & & & & & & & & & & & & & \\
\hline 4 Prestige Points & 14.50 & 7.57 & $-.19^{* *}$ & $-.29^{* *}$ & $-.18^{* *}$ & & & & & & & & & & & & & & & \\
\hline 5 Age & 29.90 & 7.45 & .02 & .03 & .03 & $-.17^{* *}$ & & & & & & & & & & & & & & \\
\hline 6 Gender (1=Males) & $\begin{array}{r}.55 \\
\text { (\%Male) }\end{array}$ & & -.04 & .07 & .08 & $-.14^{* *}$ & $.27^{* *}$ & & & & & & & & & & & & & \\
\hline 7 Years Work Experience & 9.92 & 7.89 & .02 & -.03 & .07 & -.09 & $.89^{* *}$ & $.21^{* *}$ & & & & & & & & & & & & \\
\hline 8 Vertical Collectivism & 3.65 & .96 & $.12^{* *}$ & $-.14^{* *}$ & -.05 & $.13^{* *}$ & .08 & -.04 & $.11^{*}$ & $(.54)$ & & & & & & & & & & \\
\hline 9 Vertical Individualism & 4.34 & .81 & $-.10^{*}$ & .04 & .00 & $.10^{*}$ & $-.16^{* *}$ & .07 & $-.14^{* *}$ & $.18^{* *}$ & (.69) & & & & & & & & & \\
\hline 10 Horizontal Collectivism & 4.84 & .71 & $.17^{* *}$ & $-.15^{* *}$ & -.07 & $.11^{*}$ & .03 & $-.10^{*}$ & .06 & $.29^{* *}$ & $.11^{*}$ & (.65) & & & & & & & & \\
\hline 11 Horizontal Individualism & 4.50 & .94 & -.03 & $-.13^{* *}$ & $.12^{* *}$ & $.11^{*}$ & $-.12^{* *}$ & $-.09^{*}$ & .03 & -.01 & $.21^{* *}$ & .05 & (.73) & & & & & & & \\
\hline 12 Social Adjustment & 4.22 & 1.02 & -.04 & -.02 & $-.20^{* *}$ & $.33^{* *}$ & $-.21^{* *}$ & -.07 & $-.22^{* *}$ & .09 & $.28^{* *}$ & $.12^{* *}$ & .05 & $(.65)$ & & & & & & \\
\hline 13 Brazil & $\begin{array}{r}.10 \\
\text { (\% of Sample) }\end{array}$ & & .04 & .01 & -.03 & -.05 & .08 & -.03 & .08 & $-.18^{* *}$ & $-.27^{* *}$ & .06 & $-.20^{* *}$ & $-.16^{* *}$ & & & & & & \\
\hline 14 China & $\begin{array}{r}.13 \\
\text { (\% of Sample) }\end{array}$ & & .05 & .00 & -.03 & -.08 & $.22^{* *}$ & $.09^{*}$ & .04 & $.13^{* *}$ & .08 & $.17^{* *}$ & $-.24^{* *}$ & .08 & $-.13^{* *}$ & & & & & \\
\hline 15 India & $\begin{array}{r}.15 \\
(\% \text { of Sample) }\end{array}$ & & -.01 & $-.21^{* *}$ & $.14^{* *}$ & $.20^{* *}$ & $-.44^{* *}$ & $-.13^{* *}$ & $-.25^{* *}$ & $.34^{* *}$ & $.22^{* *}$ & $.14^{* *}$ & $.23^{* *}$ & -.04 & $-.14^{* *}$ & $-.17^{* *}$ & & & & \\
\hline 16 Ireland & $\begin{array}{r}.09 \\
\text { (\% of Sample) }\end{array}$ & & -.03 & .02 & $.11^{*}$ & $-.12^{* *}$ & $.30^{* *}$ & $.10^{*}$ & $.29^{* *}$ & -.02 & .01 & -.03 & $.12^{* *}$ & $-.20^{* *}$ & $-.10^{*}$ & $-.12^{* *}$ & $-.13^{* *}$ & & & \\
\hline 17 Lithuania & $\begin{array}{r}.15 \\
\text { (\% of Sample) }\end{array}$ & & .06 & .07 & $-.23^{* *}$ & $.10^{*}$ & $-.10^{*}$ & $-.11^{*}$ & $-.17^{* *}$ & $-.16^{* *}$ & .05 & -.06 & -.08 & .06 & $-.14^{* *}$ & $-.17^{* *}$ & $-.18^{* *}$ & $-.13^{* *}$ & & \\
\hline 18 Turkey & $\begin{array}{r}.17 \\
\text { (\% of Sample) }\end{array}$ & & $-.09^{*}$ & .00 & .04 & .09 & $-.25^{* *}$ & -.05 & $-.39^{* *}$ & -.06 & .06 & -.03 & -.01 & $.30^{* *}$ & $-.15^{* *}$ & $-.18^{* *}$ & $-.19^{* *}$ & $-.14^{* *}$ & $-.19^{* *}$ & \\
\hline 19 US & $\begin{array}{r}.20 \\
(\% \text { of Sample) }\end{array}$ & & -.01 & .07 & .03 & $-.13^{* *}$ & $.32^{* *}$ & $.13^{* *}$ & $.35^{* *}$ & -.07 & $-.17^{* *}$ & $-.21^{* *}$ & $.14^{* *}$ & $-.10^{*}$ & $-.17^{* * *}$ & $-.20^{* *}$ & $-.21^{* *}$ & $-.16^{* *}$ & $-.21^{* *}$ & $-.23^{* *}$ \\
\hline
\end{tabular}

Alpha reliabilities are in parentheses on the diagonal. 
Table 2

Model Variables by Country

\begin{tabular}{|c|c|c|c|c|c|c|c|c|c|c|c|c|c|c|}
\hline Country & Brazil & $n=51$ & China & $n=66$ & India & $n=52$ & Ireland & $n=45$ & Lithuania & $n=77$ & Turkey & $n=83$ & US & $n=101$ \\
\hline & Mean & s.d. & Mean & s.d. & Mean & s.d. & Mean & s.d. & Mean & s.d. & Mean & s.d. & Mean & s.d. \\
\hline $\begin{array}{l}\text { Vertical } \\
\text { Collectivism }\end{array}$ & 3.1 & 1.00 & 3.96 & .84 & 4.40 & .67 & 3.59 & .87 & 3.3 & .97 & 3.55 & .78 & 3.54 & .90 \\
\hline $\begin{array}{l}\text { Horizontal } \\
\text { Individualism }\end{array}$ & 3.93 & .96 & 3.93 & 1.03 & 5.01 & .84 & 4.86 & .69 & 4.3 & .82 & 4.48 & .94 & 4.77 & .71 \\
\hline $\begin{array}{l}\text { Vertical } \\
\text { Individualism }\end{array}$ & 3.68 & .90 & 4.51 & .68 & 4.76 & .78 & 4.36 & .68 & 4.44 & .70 & 4.45 & .78 & 4.06 & .77 \\
\hline $\begin{array}{l}\text { Horizontal } \\
\text { Collectivism }\end{array}$ & 4.97 & .72 & 5.15 & .62 & 5.08 & .60 & 4.78 & .64 & 4.75 & .76 & 4.80 & .65 & 4.56 & .77 \\
\hline Social Adjustment & 3.96 & 1.08 & 4.72 & 1.73 & 4.27 & .83 & 3.57 & 1.28 & 4.32 & 1.00 & 4.91 & .90 & 4.06 & .89 \\
\hline $\begin{array}{l}\text { Harmonious Work } \\
\text { Environment }\end{array}$ & 28.33 & 11.53 & 28.56 & 10.21 & 26.83 & 10.76 & 26.04 & 7.73 & 28.70 & 11.71 & 25.00 & 10.30 & 26.87 & 10.97 \\
\hline $\begin{array}{l}\text { Remuneration and } \\
\text { Advancement }\end{array}$ & 31.71 & 11.22 & 31.52 & 10.63 & 24.52 & 9.25 & 32.07 & 8.06 & 33.44 & 13.14 & 31.57 & 13.00 & 33.11 & 11.38 \\
\hline Prestige & 13.45 & 6.24 & 12.91 & 6.02 & 18.88 & 8.22 & 11.71 & 6.67 & 16.13 & 6.83 & 15.96 & 7.90 & 12.60 & 8.03 \\
\hline
\end{tabular}


Table 3a

Regression Results

Harmonious Work Environment

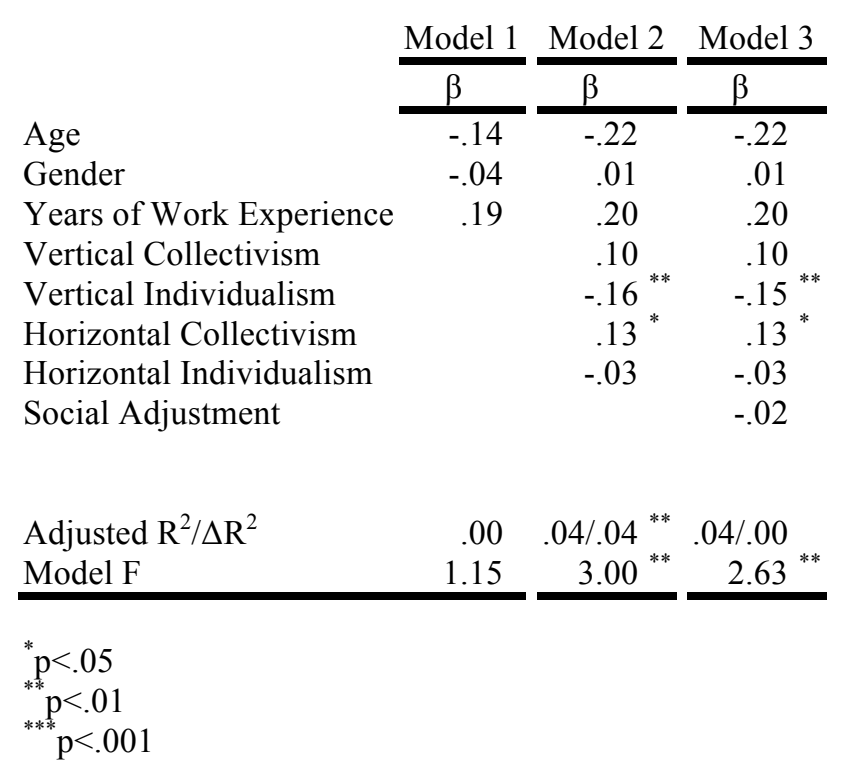


Table 3b

Regression Results

Remuneration/Opportunities for Advancement

\begin{tabular}{|c|c|c|c|}
\hline & $\frac{\text { Model } 1}{\beta}$ & $\frac{\text { Model } 2}{\beta}$ & $\frac{\text { Model } 3}{\beta}$ \\
\hline Age & -.05 & -.03 & -.03 \\
\hline Gender & .01 & -.03 & -.03 \\
\hline Years of Work Experience & .00 & .03 & .03 \\
\hline Vertical Collectivism & & -.09 & -.09 \\
\hline Vertical Individualism & & $.11 *$ & $.12 *$ \\
\hline Horizontal Collectivism & & -.12 * & -.11 * \\
\hline Horizontal Individualism & & $-.13^{*}$ & $-.13 *$ \\
\hline Social Adjustment & & & -.04 \\
\hline Adjusted $\mathrm{R}^{2} / \Delta \mathrm{R}^{2}$ & .00 & $.03 / .03^{* *}$ & $.03 / .00$ \\
\hline Model F & .27 & $2.71^{* *}$ & $2.44^{*}$ \\
\hline
\end{tabular}


Table 3c

\section{Regression Results}

Meaningful Work

\begin{tabular}{|c|c|c|c|}
\hline & Model 1 & Model 2 & Model 3 \\
\hline & $\beta$ & $\bar{\beta}$ & $\beta$ \\
\hline Age & .13 & .21 & .20 \\
\hline Gender & .10 & .09 & .08 \\
\hline Years of Work Experience & -.07 & -.13 & -.17 \\
\hline Vertical Collectivism & & -.06 & -.03 \\
\hline Vertical Individualism & & -.02 & .03 \\
\hline Horizontal Collectivism & & -.05 & -.03 \\
\hline Horizontal Individualism & & $.14^{* *}$ & $.13^{* *}$ \\
\hline Social Adjustment & & & $-.19^{* *}$ \\
\hline Adjusted $R^{2} / \Delta R^{2}$ & .01 & $.03 / .02 *$ & $.06 / .03^{* *}$ \\
\hline Model F & 2.51 & $2.58^{*}$ & $3.94^{* * *}$ \\
\hline $\begin{array}{l}{ }^{*} \mathrm{p}<.05 \\
{ }_{* * *} \mathrm{p}<.01 \\
{ }^{* * *} \mathrm{p}<.001\end{array}$ & & & \\
\hline
\end{tabular}


Table 3d

Regression Results

Employer Prestige

\begin{tabular}{|c|c|c|c|}
\hline & Model 1 & Model 2 & Model 3 \\
\hline & $\beta$ & $\beta$ & $\beta$ \\
\hline Age & .01 & -.03 & -.01 \\
\hline Gender & -.08 & -.07 & -.05 \\
\hline Years of Work Experience & -.13 & -.12 & -.06 \\
\hline Vertical Collectivism & & $.13^{*}$ & .07 \\
\hline Vertical Individualism & & .07 & -.01 \\
\hline Horizontal Collectivism & & .06 & .02 \\
\hline Horizontal Individualism & & .07 & .08 \\
\hline Social Adjustment & & & $.32^{* *}$ \\
\hline Adjusted $\mathrm{R}^{2} / \Delta \mathrm{R}^{2}$ & $.02^{*}$ & $.05 / .03^{* *}$ & $.13 / .08^{* *}$ \\
\hline Model F & $3.33^{*}$ & $3.31^{* *}$ & $7.30^{* * *}$ \\
\hline
\end{tabular}

